\title{
Impact of Realistic Controls on Building Energy Consumption and Comfort
}

\author{
Rohini Brahme ${ }^{1}$, Aswath Mukundan ${ }^{2}$, Rakesh Goel ${ }^{1}$ \\ ${ }^{1}$ Lennox International Inc., Texas, USA \\ ${ }^{2}$ Lennox India Technology Centre, Chennai, India
}

\begin{abstract}
Increasingly, the control logic of HVAC system plays a significant role in defining the system's operational efficiency and ability to establish and maintain the desired indoor conditions. Whole building performance simulation tools (EnergyPlus, eQuest, etc.) can be used to evaluate the impact of various control strategies, with the caveat that most of these strategies are predefined, with limited options for customization. These tools assume ideal control logic and cannot predict the impact of equipment cycling accurately. In this paper, cosimulation of building model (in EnergyPlus) with equipment and control model (in Matlab) is used to study the impact of cycling and of control parameter on comfort and HVAC energy consumption, to understand the significance of actual control logic for building performance simulation. Preliminary analysis of few cases shows that this setup allows for a better prediction of cycling losses. It allows one to study the impact of control parameters on annual energy consumption and comfort indices. More importantly, this setup opens up the analysis of any number of enhancements to typical control strategies which are pre-defined in whole building simulation tools.
\end{abstract}

\section{Introduction}

HVAC systems operate to establish and maintain conditions comfortable for human occupancy in the buildings. However, these systems consume a significant portion, around $40-45 \%$, of the total energy used in the building (DoE 2010). Therefore, it is essential to improve the performance of the HVAC system in different ways possible. HVAC system consist of different components and one of the ways to improve the overall system performance is by improving the design of the individual components like enhancing the heat transfer efficiency of the heat exchangers viz. the condenser and the evaporator, improved compressor efficiency etc.

Apart from the design of individual components that constitute a HVAC system, the efficiency of the
HVAC system is also influenced by operating thermal conditions i.e. dry bulb temperature and relative humidity of ambient and thermal zone served by the HVAC system. The ambient condition varies widely from place to place and the desired indoor conditions depend on the occupant and can vary drastically too. However, in this work the desired indoor conditions are assumed to be the same for different simulation cases. Thus it is possible that identical HVAC systems, i.e. those which include components of same design, may end up operating with different performance in different locations.

In such cases, the control logic governing the operation of the system may have an influence on the system performance. Understanding the influence of control parameters on performance of HVAC system requires the simulation of the actual operation cycle of the HVAC system. Building performance simulation tools simulate different energy interactions in a building and can predict the cooling load profile against which the HVAC system has to operate. In this study, two building types have been considered - a small office building and a typical single family residence. Both the models are taken from the reference building prototype models developed by PNNL (PNNL Commercial and PNNL Residential).

- A $35 \mathrm{~kW}$ (10 ton) two stage roof top air conditioning unit serves a zone in a small office building. This unit can operate in different modes, namely part load and full load, depending on the indoor requirements and outdoor conditions.

- A $10.5 \mathrm{~kW}$ (3 ton) variable speed split system serves the single family residence.

The dynamics of HVAC system controls can change in timescale of minutes or less. In this study, the time step of one minute is used for the annual simulations, since that is the minimum time step possible in Energyplus, and it also works reasonably well for understanding the impact of control parameters. Further, the control logic provided in EnergyPlus is different from the actual system and therefore co- 


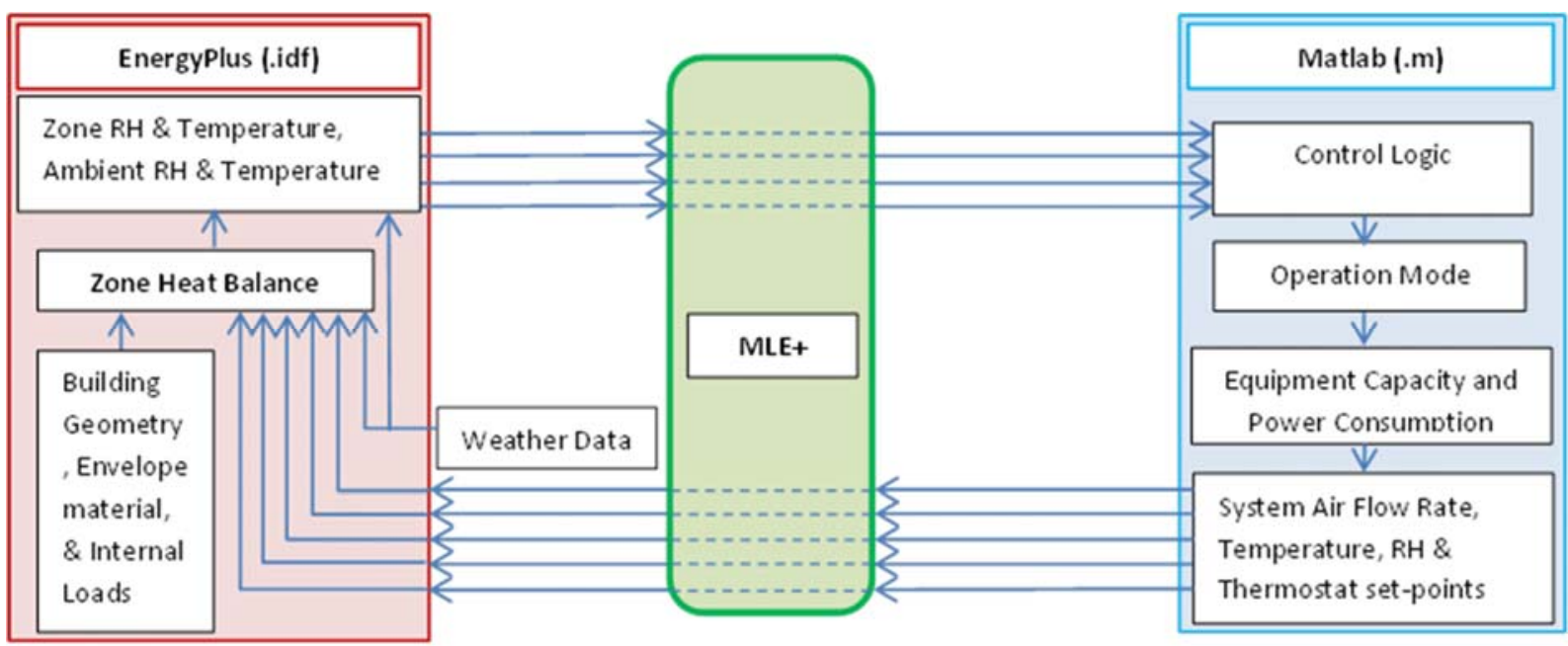

Figure 1: EnergyPlus Matlab co-simulation setup.

simulation is used here, modelling the building in EnergyPlus and the equipment and control in Matlab. The transition between different stages of HVAC equipment is very different from steady state operation at these stages in terms of the cooling capacity and energy consumption of the HVAC system. Both ideal and actual transitions between the operating modes have been considered in annual simulation of the office building to understand the impact of the realistic controls. For the single family residence, only the steady state simulations are used currently. On the controls side, the effect of minimum on time, minimum off time, low stage run time, and PI gains, are studied to understand the impact of PI control logic on energy consumption and comfort.

\section{Method}

Annual building energy simulations were carried out for a small office building consisting of two zones viz. Office Space Main and Office Space 1 with area of $444 \mathrm{~m}^{2}\left(4779 \mathrm{ft}^{2}\right)$ and $67 \mathrm{~m}^{2}\left(721 \mathrm{ft}^{2}\right)$ respectively. To study the impact of the realistic controls, a two stage roof top unit of $35 \mathrm{~kW}$ (10 ton) cooling capacity is considered for meeting the cooling demands of Main Office Zone. The cooling demand of the zone Office Space 1 is considered to be met by an ideal HVAC system (using EnergyPlus' system definition). The thermostat cooling set-point for the zones is always at $23.89^{\circ} \mathrm{C}\left(75^{\circ} \mathrm{F}\right)$.

The building is modelled in EnergyPlus 8.6.0 and includes the building geometry, envelope construction and material, infiltration, occupancy, lighting and equipment schedules. The ideal HVAC system is modelled using Ideal Loads Air System object in EnergyPlus. To simulate the real time operation of the HVAC system for the Office Space
Main, the equipment is modelled using performance curves based on lab test data and its control logic is implemented in Matlab. The performance curves are generated for both steady state operation (when the system is in Stage 1, in stage 2, or OFF) as well as transient state (the transition between $\mathrm{ON}$ to OFF, $\mathrm{OFF}$ to $\mathrm{ON}$ etc.) The steady state performance curves are similar to what is used commonly in energyplus, and can be generated from manufacturer's published data. The performance curves for transient state modelling need data from lab testing.

The single family residential building consists of a 2 storey conditioned zone and an unconditioned attic zone with floor areas of $223 \mathrm{~m}^{2}\left(2400 \mathrm{ft}^{2}\right)$ and 111.5 $\mathrm{m}^{2}\left(1200 \mathrm{ft}^{2}\right)$ respectively. The thermostat cooling set-point is at $23.88{ }^{\circ} \mathrm{C}\left(75^{\circ} \mathrm{F}\right)$ with a setback to $26.67{ }^{\circ} \mathrm{C}\left(80^{\circ} \mathrm{F}\right)$ during the day time, the period of reduced occupancy between 8:00 and 18:00 hours.

The building model in EnergyPlus and equipment model in Matlab are connected using MLE+ for cosimulation. MLE+ is an open-source Matlab/ Simulink toolbox developed by Nghiem, Truong X (2010) et al. at mLAB, the Real Time Embedded Lab at the University of Pennsylvania. MLE+ integrated and adapted source code from the BCVTB and provides a more direct coupling between Matlab and EnergyPlus (from discussion with Michael Wetter at LBNL).

The simulation setup is as shown in Figure 1. It broadly consists of an EnergyPlus input file, a Matlab script file and a variable configuration file. For each time-step, EnergyPlus performs the zone heat balance considering the ambient conditions from weather data, internal loads and system parameters and finds the resulting zone thermal conditions. The zone and ambient conditions namely, temperature and relative humidity, are sent to Matlab at each time-step. The 
control logic in Matlab determines the operating mode of the system, i.e. stage 1 or stage 2 and transient or steady state operation, and accordingly the equipment capacity and its power consumption for that time-step are determined. From these values, the system air flow rate, temperature and relative humidity are calculated and together with the zone thermostat set-point are sent back to EnergyPlus for zone heat balance in the subsequent time-step. On an average, the annual simulation runs took 15 to 20 minutes for completion.

Table 1: Variables for co-simulation.

\begin{tabular}{|c|c|c|}
\hline Source & $\begin{array}{l}\text { EnergyPlus } \\
\text { Object Type }\end{array}$ & Variable \\
\hline EnergyPlus & Output: Variable & $\begin{array}{l}\text { Site Outdoor Air Dry } \\
\text { Bulb Temperature }\end{array}$ \\
\hline EnergyPlus & Output: Variable & $\begin{array}{c}\text { Site Outdoor Air } \\
\text { Relative Humidity }\end{array}$ \\
\hline EnergyPlus & Output: Variable & $\begin{array}{c}\text { Zone Air } \\
\text { Temperature }\end{array}$ \\
\hline EnergyPlus & Output: Variable & $\begin{array}{c}\text { Zone Air Relative } \\
\text { Humidity }\end{array}$ \\
\hline Matlab & $\begin{array}{c}\text { ExternalInterface: } \\
\text { Actuator }\end{array}$ & $\begin{array}{c}\text { Ideal Loads Air } \\
\text { System Air Mass } \\
\text { Flow Rate }\end{array}$ \\
\hline Matlab & $\begin{array}{c}\text { ExternalInterface: } \\
\text { Actuator }\end{array}$ & $\begin{array}{c}\text { Ideal Loads Air } \\
\text { System Air } \\
\text { Temperature } \\
\end{array}$ \\
\hline Matlab & $\begin{array}{c}\text { ExternalInterface: } \\
\text { Actuator }\end{array}$ & $\begin{array}{c}\text { Ideal Loads Air } \\
\text { System Air Humidity } \\
\text { Ratio }\end{array}$ \\
\hline Matlab & $\begin{array}{c}\text { ExternalInterface: } \\
\text { Schedule }\end{array}$ & $\begin{array}{c}\text { Heating Setpoint } \\
\text { Thermostat Schedule }\end{array}$ \\
\hline Matlab & $\begin{array}{l}\text { ExternalInterface: } \\
\text { Schedule }\end{array}$ & $\begin{array}{c}\text { Cooling Setpoint } \\
\text { Thermostat Schedule }\end{array}$ \\
\hline
\end{tabular}

\section{Results and Discussion}

\section{Office building simulation}

Air conditioner cycling is generally modelled using average performance degradation effects of cycling over a given time step rather than modelling individual on-off cycles. Cyclic losses are accounted for by increasing the required air conditioner runtime to meet the building load. The runtime factor is a fun- ction of degradation coefficient (CD), the factor of efficiency loss due to the cycling of the unit (ASHRAE Standard 116-1995). The degradation coefficient $\mathrm{CD}$ for cooling cyclic operation is calculated as follows.

$$
C D=\left\{1-\frac{E E R_{c y c}}{E E R_{S S}}\right\} /(1-C L F)
$$

The value of $\mathrm{CD}$ is typically between 0.05 (lower cycling loss) and 0.25 (higher cycling loss); Modern, single-stage air conditioners tend to have $C D$ values around 0.07 . From the results in the paper, we can see that the energy losses are almost similar to $\mathrm{CD}$, so it is reasonable to conclude that the increase in energy consumption due to cycling losses is in the same range as $\mathrm{CD}$ - i.e. from $5 \%$ to $25 \%$ (Booten, Christensen and Winkler, 2014). More often, during whole building simulations, a typical number for CD is used for all scenarios that are analysed - which results in a constant \% increase in energy consumption due to cycling.

Analysis between steady state (does not include cycling impacts) vs. transient state (this state considers the impact of cycling) shows that the cycling losses differ significantly, depending on the conditions in which the unit is operating. Two different locations, Miami and Phoenix, have been considered in this study. Table 2 summarizes the results of steady state and transient state annual simulation of the building at these locations. Miami shows a $4 \%$ increase in energy consumption due to cycling losses. This is in line with the typical $7 \%$ energy consumption increase for a modern singlestage air conditioner. The unit in the study is 2-stage unit, so we can expect the cycling losses to be less. On the other hand, Phoenix shows a $15 \%$ increase in energy consumption due to cycling. It shows that the increase in runtime, which is $3 \%$ more in Phoenix compared to Miami, translates to an $11 \%$ more increase in energy consumption due to inclusion of transients in the simulation. Considering indoor zone conditions, the impact on humidity is more pronounced due to inclusion of the transient performance curves - which model the re-evaporation of condensate on the evaporator coil (Figure 3).

Table 2: Comparison of annual steady state and transient simulation for Phoenix and Miami.

\begin{tabular}{|c|c|c|c|c|c|}
\hline Location & $\begin{array}{c}\text { Simulation } \\
\text { Type }\end{array}$ & $\begin{array}{c}\text { Total Energy } \\
{[\mathrm{kWh}]}\end{array}$ & $\begin{array}{c}\text { Hours when } \\
\text { Indoor } \mathrm{RH}>60 \% \\
\end{array}$ & $\begin{array}{c}\text { Hours when Indoor } \\
\text { Temperature }>24.2^{\circ} \mathrm{C}\left(75.5^{\circ} \mathrm{F}\right) \\
\end{array}$ & $\begin{array}{c}\text { Total Operating } \\
\text { Hours } \\
\end{array}$ \\
\hline \multirow{2}{*}{ Miami } & Steady State & 25218 & 1152 & 452 & 4958 \\
\hline & Transient State & 26138 & 2137 & 364 & 5715 \\
\hline \multirow{2}{*}{ Phoenix } & Steady State & 24250 & 0 & 629 & 4215 \\
\hline & Transient State & 28405 & 0 & 661 & 5042 \\
\hline
\end{tabular}




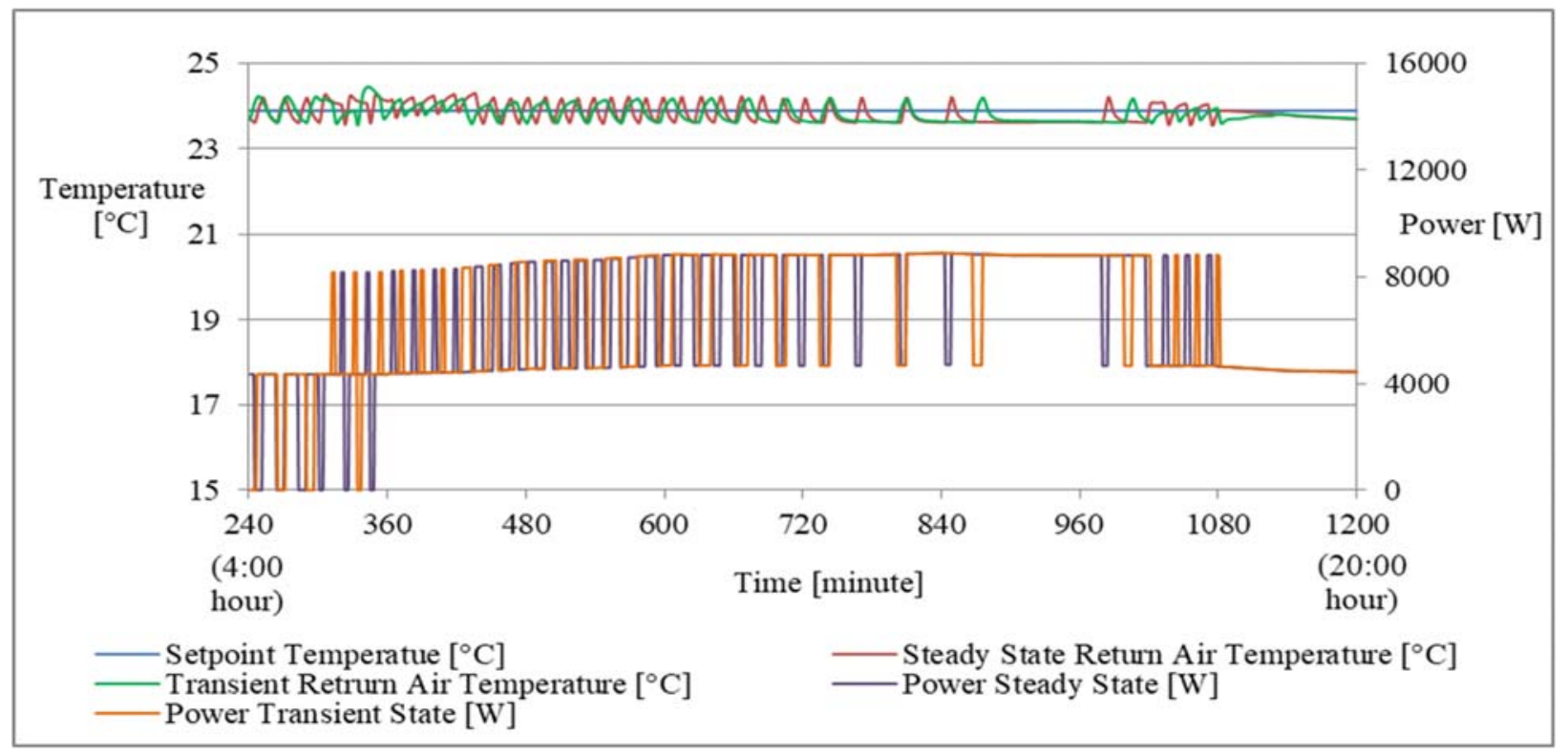

Figure 2: Comparison of indoor temperature and power consumption for steady state and transient simulation for 31 July.

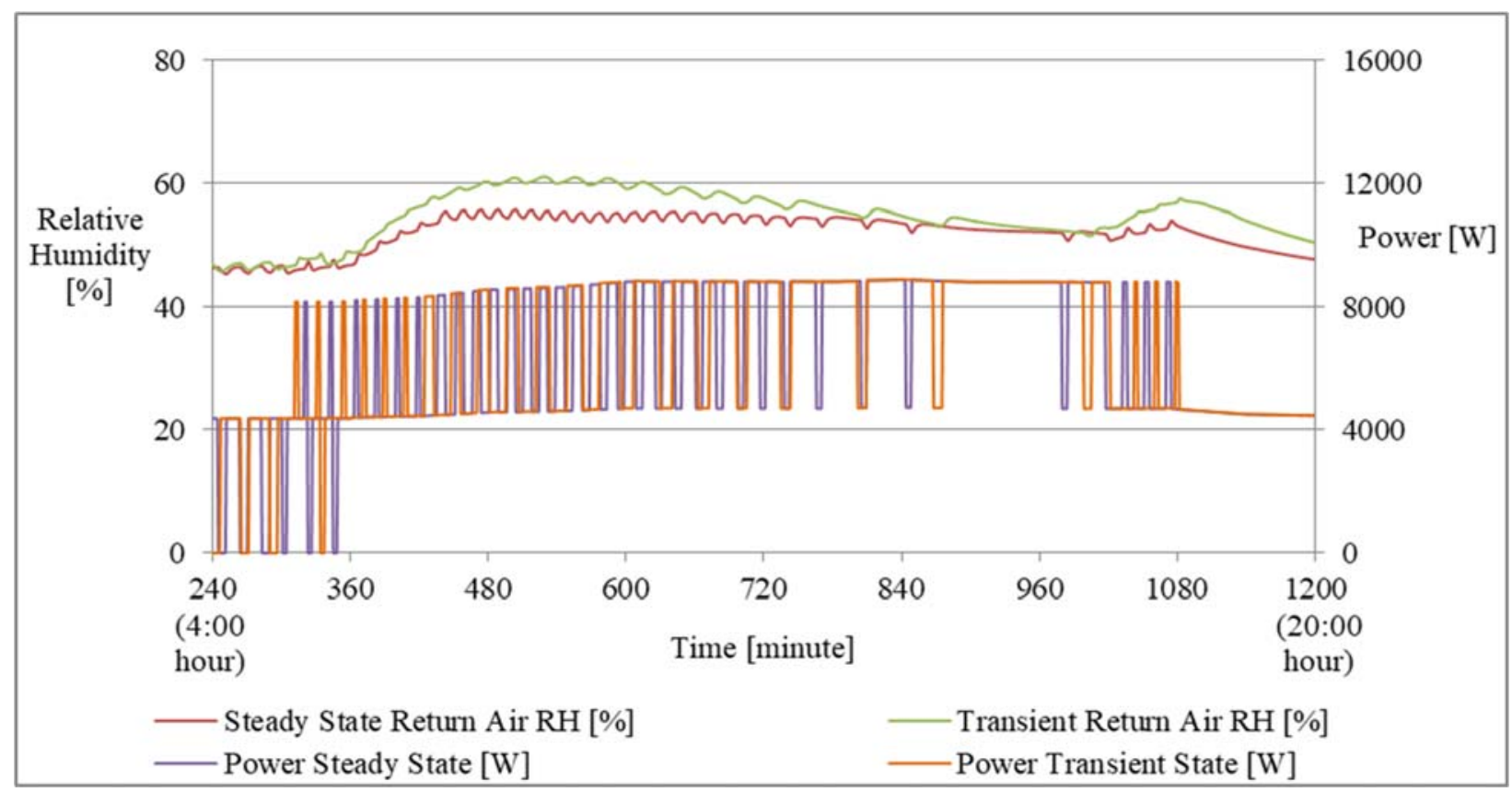

Figure 3: Comparison of indoor relative humidity and Power consumption for steady state and transient simulation for 31 July.

The simulation of realistic control allows one to consider the impact of control parameters on energy consumption (Minimum on time, Minimum off time, Low stage time setting in the case of on-off control logic; Minimum on time, Minimum off time Cycles per hour, Proportional and Integral gains in case of PI control logic).
Table 3 summarizes the results of annual simulation for the office building at Miami with different values for the HVAC system control parameters. Table 4 summarizes the results of annual simulation for the office building at Phoenix with different values for the HVAC system control parameters. In both cases the transients are included. 
Table 3: Annual energy consumption and temperature set-point unmet hours at Miami at different control settings.

\begin{tabular}{|c|c|c|c|c|c|c|}
\hline $\begin{array}{c}\text { Min. On } \\
\text { Time } \\
{[\mathbf{m i n}]}\end{array}$ & $\begin{array}{c}\text { Min. Off } \\
\text { Time } \\
{[\mathbf{m i n}]}\end{array}$ & $\begin{array}{c}\text { Low Stage } \\
\text { Time Setting } \\
{[\mathbf{m i n}]}\end{array}$ & $\begin{array}{c}\text { Total } \\
\text { Energy } \\
{[\mathbf{k W h}]}\end{array}$ & $\begin{array}{c}\text { Number of hours } \\
\text { when Indoor RH }> \\
\mathbf{6 0} \%\end{array}$ & $\begin{array}{c}\text { Number of hours when } \\
\text { Indoor Temperature } \\
\mathbf{2 4 . 2} \mathbf{}^{\circ} \mathbf{C}\left(\mathbf{7 5 . 5} \mathbf{}^{\circ}\right)\end{array}$ & $\begin{array}{c}\text { Total Annual } \\
\text { Operating } \\
\text { Hours }\end{array}$ \\
\hline 3 & 3 & 10 & 26090 & 2157 & 378 & 5679 \\
\hline 3 & 3 & 12 & 26137 & 2142 & 368 & 5696 \\
\hline 3 & 3 & 15 & 26138 & 2137 & 364 & 5715 \\
\hline 3 & 3 & 20 & 26123 & 2110 & 360 & 5735 \\
\hline 4 & 4 & 10 & 26030 & 2314 & 478 & 5691 \\
\hline 5 & 5 & 10 & 25983 & 2462 & 587 & 5676 \\
\hline 6 & 6 & 10 & 25939 & 2529 & 639 & 5672 \\
\hline 4 & 4 & 20 & 26087 & 2145 & 551 & 5758 \\
\hline 5 & 5 & 20 & 26044 & 2183 & 570 & 5769 \\
\hline 6 & 6 & 20 & 26023 & 2233 & 648 & 5772 \\
\hline
\end{tabular}

Table 4: Annual energy consumption and temperature set-point unmet hours at Phoenix at different control settings.

\begin{tabular}{|c|c|c|c|c|c|c|}
\hline $\begin{array}{c}\text { Min. On } \\
\text { Time } \\
{[\mathbf{m i n}]}\end{array}$ & $\begin{array}{c}\text { Min. Off } \\
\text { Time } \\
{[\mathbf{m i n}]}\end{array}$ & $\begin{array}{c}\text { Low Stage } \\
\text { Time Setting } \\
{[\mathbf{m i n}]}\end{array}$ & $\begin{array}{c}\text { Total } \\
\text { Energy } \\
{[\mathbf{k W h}]}\end{array}$ & $\begin{array}{c}\text { Number of hours } \\
\text { when Indoor RH }> \\
\mathbf{6 0} \%\end{array}$ & $\begin{array}{c}\text { Number of hours when } \\
\text { Indoor Temperature } \\
\left.\mathbf{2 4 . 2} \mathbf{}^{\mathbf{C}} \mathbf{( 7 5 . 5} \mathbf{}^{\circ} \mathbf{F}\right)\end{array}$ & $\begin{array}{c}\text { Total Annual } \\
\text { Operating } \\
\text { Hours }\end{array}$ \\
\hline 3 & 3 & 10 & 28326 & 0 & 709 & 4918 \\
\hline 3 & 3 & 12 & 28348 & 0 & 670 & 4991 \\
\hline 3 & 3 & 15 & 28405 & 0 & 661 & 5042 \\
\hline 3 & 3 & 20 & 28389 & 0 & 676 & 5087 \\
\hline 4 & 4 & 10 & 28340 & 0 & 900 & 4887 \\
\hline 5 & 5 & 10 & 28728 & 0 & 956 & 4843 \\
\hline 6 & 6 & 10 & 28965 & 0 & 798 & 4804 \\
\hline 4 & 4 & 20 & 28386 & 0 & 859 & 5078 \\
\hline 5 & 5 & 20 & 28646 & 0 & 886 & 5053 \\
\hline 6 & 6 & 20 & 28821 & 0 & & 5027 \\
\hline
\end{tabular}

Comparing the combinations that result in minimum energy value vs. the maximum energy value, the difference in energy consumption is about $1 \%$ to $2 \%$. At first, this does not appear significant, but if we consider the impact on humidity, $4 \%$ (7\% of System ON hours) less hours are outside the humidity comfort criteria for Miami. Similarly, for indoor temperature, looking at the Figure 4 and 5, we can see that changing the min-on/off time increases the amplitude of temperature. One would need to consider this parameter depending on how tight the control of temperature is required. On the other hand, in this study, for the limited number of options considered, the minimum time for a stage does not have much impact on comfort, so one could select this parameter based on just energy criteria, if it makes a difference.

\section{Single family residence simulation}

The single family residence simulation uses PI control logic. In addition to minimum on/off time and cycles per hour parameter used in on/off control, PI control has additional parameters related to proportional and integral gains. Figure 6 shows the comparison between indoor temperature for various typical combination of proportional and integral gains, keeping the other parameters constant. As can be seen, the cycling varies quite a bit based on the parameters used, and also results in $5-7 \%$ (7\% for no setback scenario - not detailed in the paper) HVAC energy consumption increase $(\sim 2-4 \%$ energy consumption at the whole building level). To put the data in perspective, a typical retrofit involving window upgrades (in both residential and commercial buildings) show negligible savings (2-5\% range at the 


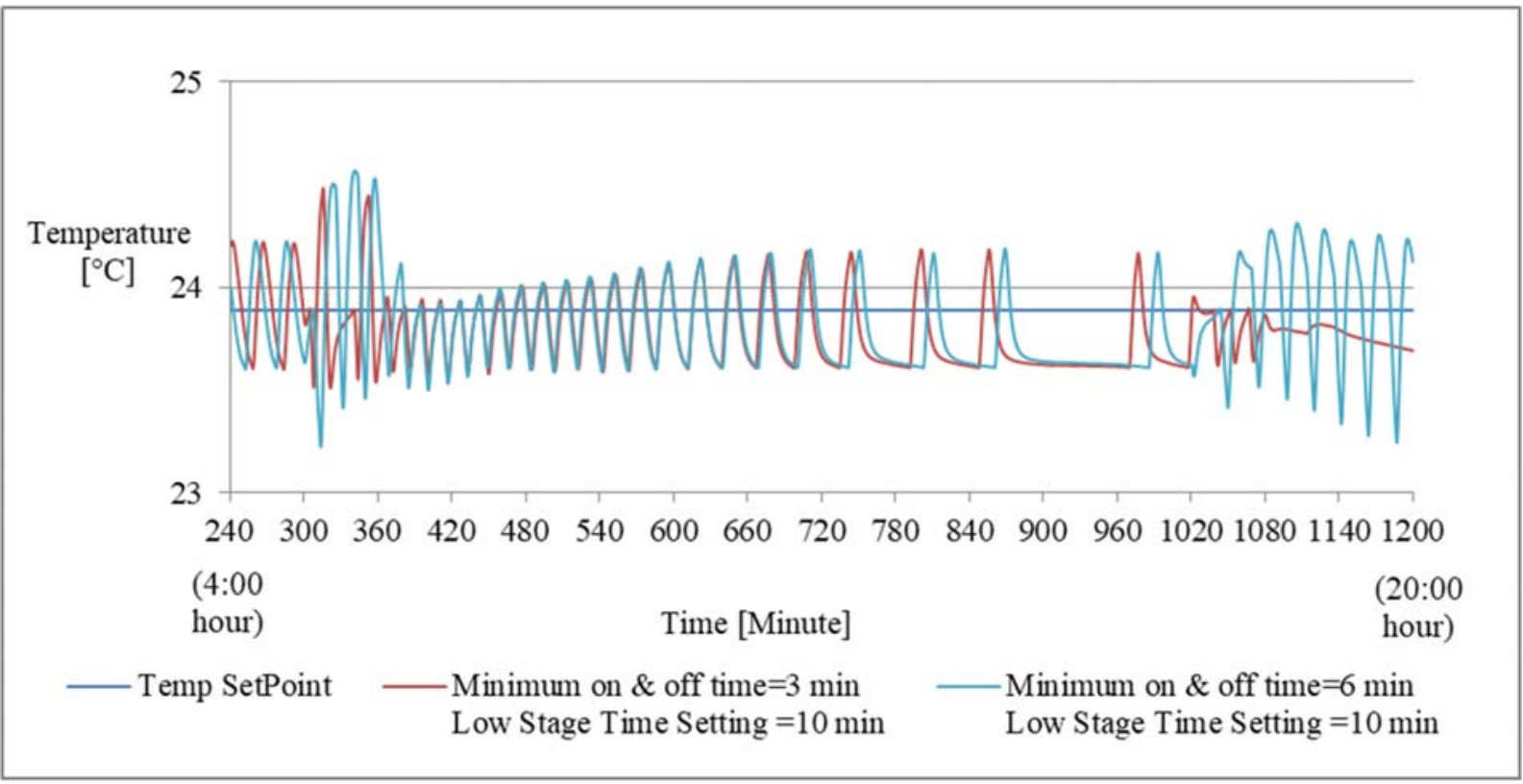

Figure 4: Effect of minimum on and off time setting of HVAC system on indoor temperature.

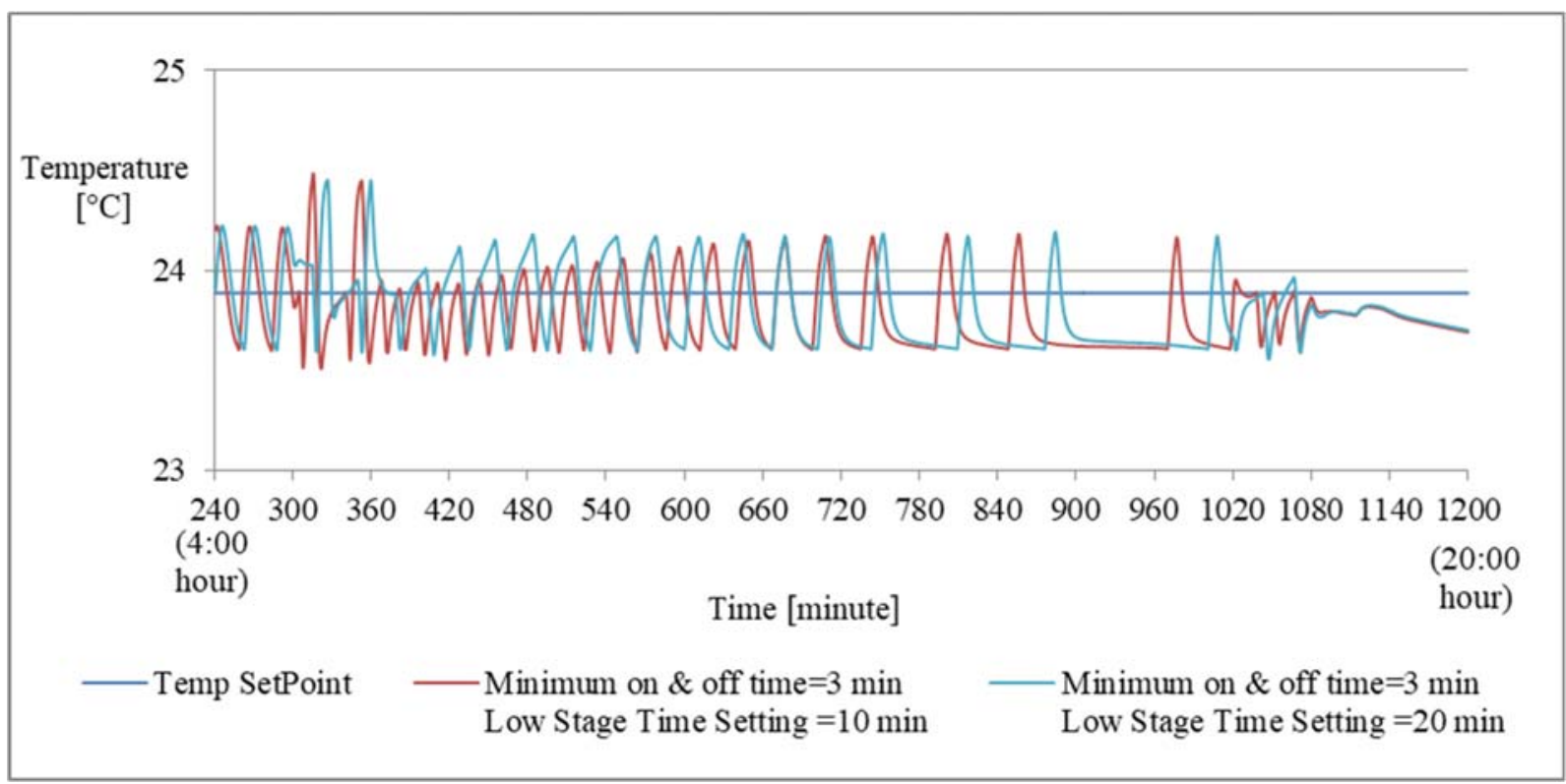

Figure 5: Effect of low stage time setting of HVAC system on indoor temperature.

whole building level) and in almost all cases not costeffective (Sam Cohen, Charles Goldman and Jeff Harris, 1991).

\section{Conclusions}

This paper describes the advantages of simulating actual control logic in conjunction with building simulation. From a control logic developer's standpoint, this allows him to consider the validity of the control parameters for all conditions that the equipment would be subjected to, instead of considering a few common scenarios. As the results related to cycling losses analysis show, in some cases, the savings and indoor conditions outcome is very different from what would have been obtained by traditional whole building simulation methodology. Similarly, even though the energy savings by loosely optimizing on the control parameters is not huge, when compared to typical retrofit savings, it gives similar savings, at no-cost.

In conclusion:

a. This setup allows better prediction of cycling losses. 


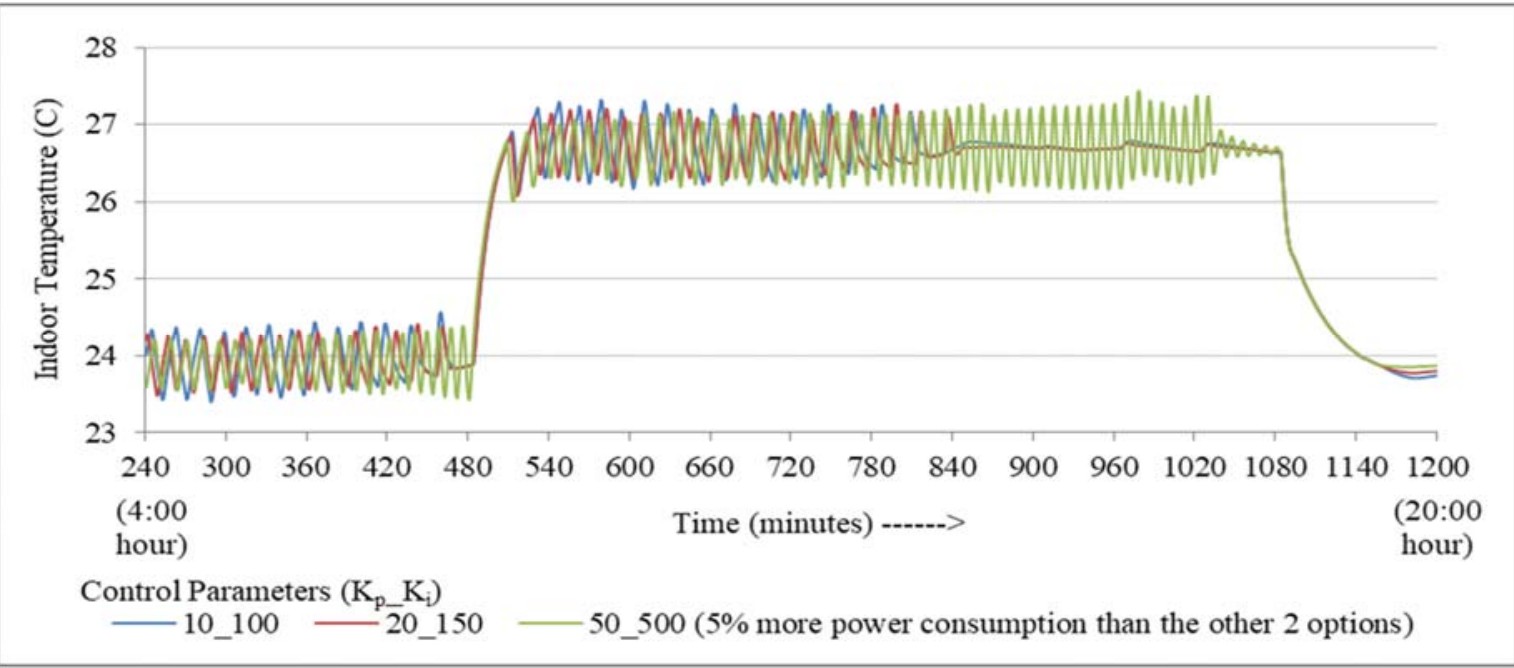

Figure 6: Comparison between indoor temperature for various combination of proportional and integral gain.

b. It allows one to study the impact of control parameters on annual energy consumption and comfort indices.

c. It helps in avoiding rule of thumb / assumptions related to control strategies, cycling, parasitic losses, etc.

d. More importantly, this setup opens up the analysis of any number of enhancements to typical control strategies which are pre-defined in whole building simulation tools.

\section{Acknowledgments}

We would like to acknowledge the contributions by Jason Hou and Jie Ma (Purdue University) in implementing the control logic in Matlab; and Yanfei $\mathrm{Li}$ (University of Alabama) in setting up the connection between EnergyPlus and Matlab to allow for co-simulation.

\section{Nomenclature}

BCVTB: Building Controls Virtual Test Bed

$\mathrm{CPH}$ : Cycles per hour

CLF: Cooling Load Factor

EER $_{\text {cyc: }}$ Cyclic Energy Efficiency Ratio

EER $_{\text {ss: }}$ Steady State Energy Efficiency Ratio

KISS: Integral Steady State Gain

KPSS: Proportional Steady State Gain

PI: Proportional Integral

PNNL: Pacific Northwest National Laboratory

RH: Relative Humidity

\section{References}

American Society of Heating, Refrigerating and AirConditioning Engineers(1995).
Methods of testing for rating seasonal efficiency of unitary air conditioners and heat pumps (ASHRAE Standard 116-1995).

Booten,C., Christensen,C., \& Winkler,J. (2014). Energy impacts of oversized air conditioners simulation study of retrofit sequence impacts NREL Technical Report NREL/TP-5500-60801, November 2014.

https://www.researchgate.net/publication/281005 875 MLE a Matlab-EnergyPlus Cosimulation_Interface

Cohen,S., Goldman,C., \& Harris,J. (1991) Energy savings and economics of retrofitting singlefamily buildings. Energy and Buildings 17, 297 311.

DoE, U. S., (2010). Energy Efficiency Trends in Residential and Commercial Buildings. August 2010.

https://www.energy.gov/sites/prod/files/2013/11/f 5/building_trends_2010.pdf

Nghiem, T.X. (2010). MLE+: A Matlab-Energyplus Co-Simulation Interface,

PNNL - Commercial Prototype Building Models, https://www.energycodes.gov/development/com mercial/prototype models

PNNL - Residential Prototype Building Model, https://www.energycodes.gov/development/reside ntial/iecc models

Trcka,M., Wetter,M., \& Hensen,J. (2007) Comparison of co-simulation approaches for building and hvac/r system simulation. Proceedings of the International IBPSA Conference. Beijing(China), 1418-1425 2007. 


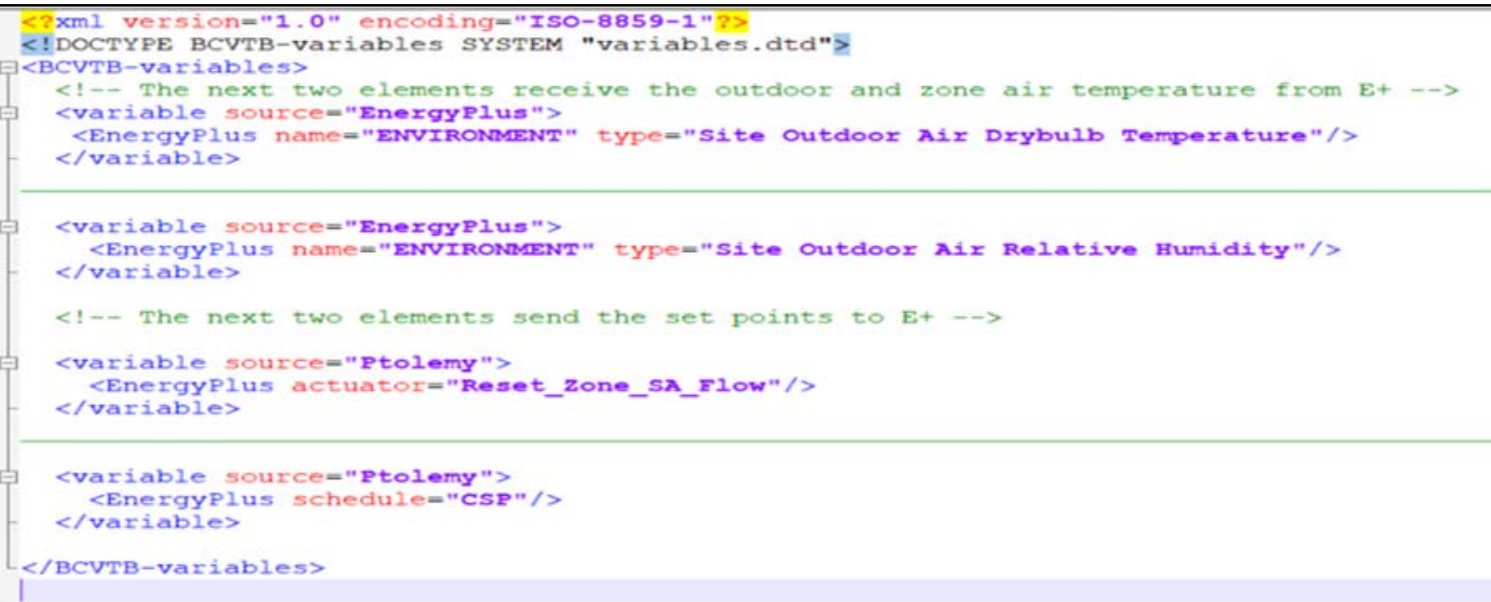

Figure 7: Variable configuration file snippet.

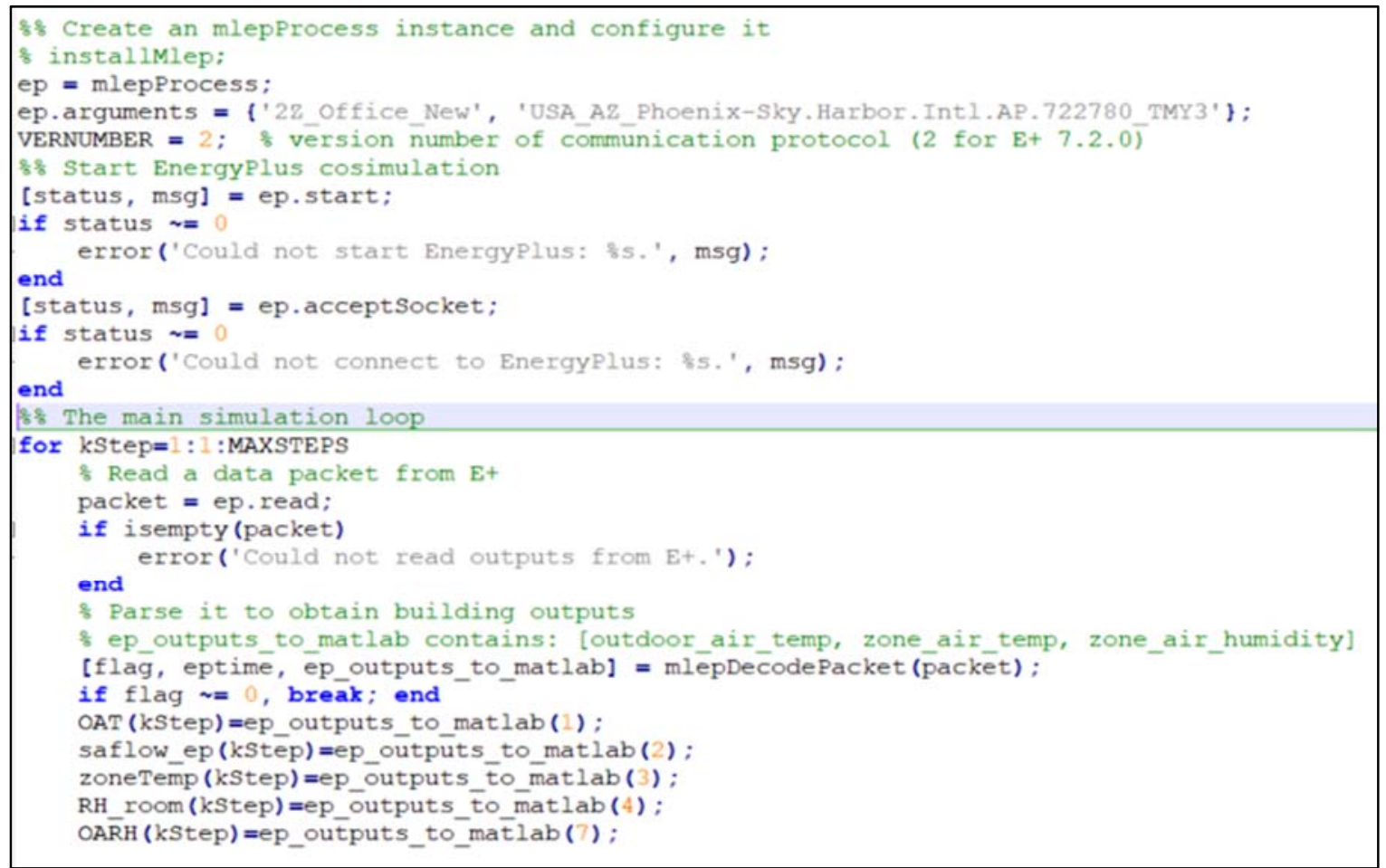

Figure 8: Matlab code snippet - Start co-simulation and collect inputs from EnergyPlus.

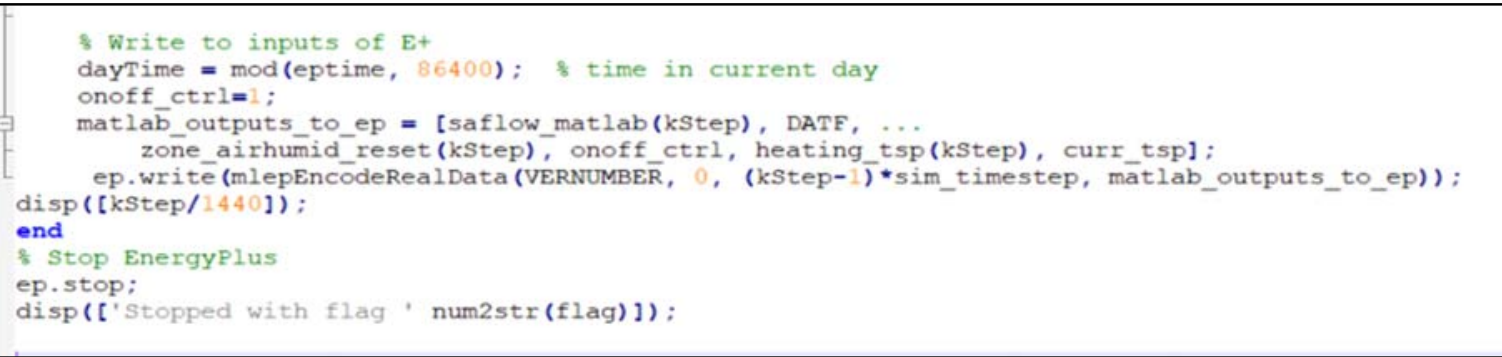

Figure 9: Matlab code snippet -Send outputs to EnergyPlus and stop co-simulation. 